SAND86-1020 • Unlimited Release $\bullet U C-80$

Printed August 1986

\title{
RSMASS: A Preliminary Reactor/Shield Mass Model for SDI Applications
}

Albert C. Marshall

Prepared by

Sandia National Laboratories

Albuquerque, New Mexico 87185 and Livermore, California 94550

for the United States Department of Energy

under Contract DE-AC04-76DP00789 


\section{DISCLAIMER}

This report was prepared as an account of work sponsored by an agency of the United States Government. Neither the United States Government nor any agency Thereof, nor any of their employees, makes any warranty, express or implied, or assumes any legal liability or responsibility for the accuracy, completeness, or usefulness of any information, apparatus, product, or process disclosed, or represents that its use would not infringe privately owned rights. Reference herein to any specific commercial product, process, or service by trade name, trademark, manufacturer, or otherwise does not necessarily constitute or imply its endorsement, recommendation, or favoring by the United States Government or any agency thereof. The views and opinions of authors expressed herein do not necessarily state or reflect those of the United States Government or any agency thereof. 


\section{DISCLAIMER}

Portions of this document may be illegible in electronic image products. Images are produced from the best available original document. 
Issued by Sandia National Laboratories, operated for the United States Department of Energy by Sandia Corporation.

NOTICE: This report was prepared as an account of work sponsored by an agency of the United States Government. Neither the United States Government nor any agency thereof, nor any of their employees, nor any of their contractors, subcontractors, or their employees, makes any warranty, excontractors, subcontractors, or their employees, makes any warranty, ex press or implied, or assumes any legal liability or responsibility for the accuracy, completeness, or usefulness of any information, apparatus, prod uct, or process disclosed, or represents that its use would not infringe privately owned rights. Reference herein to any specific commercial product, process, or service by trade name, trademark, manufacturer, or otherwise, does not necessarily constitute or imply its endorsement, recommendation or favoring by the United States Government, any agency thereof or any of their contractors or subcontractors. The views and opinions expressed herein do not necesily state or reflect those of the United States Goved herein do not necessarily state or reflect those of the United States Government,
any agency thereof or any of their contractors or subcontractors.

Printed in the United States of America Available from

National Technical Information Service

U.S. Department of Commerce

5285 Port Royal Road

Springfield, VA 22161

NTIS price codes

Printed copy: A04

Microfiche copy: A01 
Distribution Category

UC -80

SAND8 6-1020

Unlimited Release

Printed August 1986

SAND--86-1020

DE 87011573

\author{
RSMASS : \\ A PREL IMINARY REACTOR/SHIELD \\ MASS MODEL FOR SDI APPLICATIONS
}

Albert C. Marshall

Sandia National Laboratories. Albuquerque, NM 87185

\begin{abstract}
A simple mathematical model (RSMAss) has been developed to provide rapid estimates of reactor and shield masses for space-based reactor power systems. Approximations are used rather than correlations or detailed calculations to estimate the reactor fuel mass and the masses of the moderator. structure, reflector, pressure vessel, miscellaneous components, and the reactor shield. The fuel mass is determined either by neutronics limits, specific power limits, or fuel burnup limits--whichever yields the largest mass.

RSMASS requires the reactor power and energy, 24 reactor parameters, and 20 shield parameters to be specified. This parametric approach should provide good mass estimates for a very broad range of reactor types. Reactor and shield masses calculated by RSMASS were found to be in good agreement with the masses obtained from detailed calculations.
\end{abstract}

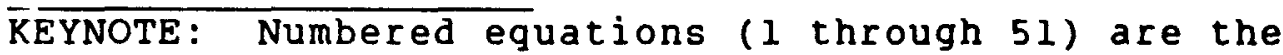
equations solved in RSMASS.

[1] Input parameters 


\section{This work was prepared for the strategic \\ This initiative Space Powe
Independent Evaluation Group (IEG).}

\section{DISCLAIMER}

This report was prepared as an account of work sponsored by an agency of the United States Government. Neither the United States Government nor any agency thereof, nor any of their employees, makes any warranty, express or implied, or assumes any legal liability or responsibility for the accuracy, completeness, or usefulness of any information, apparatus, product, or process disclosed, or represents that its use would not infringe privately owned rights. Reference herein to any specific commercial product, process, or service by trade name, trademark, manufacturer, or otherwise does not necessarily constitute or imply its endorsement, recommendation, or favoring by the United States Government or any agency thereof. The views and opinions of authors expressed herein do not necessarily state or reflect those of the United States Government or any agency thereof. 
CONTENTS

$\underline{\text { Page }}$

1.0 INTRODUCTION

2.0 SOME PRECAUTIONARY COMMENTS . . . . . . . . . . . . . 2

3.0 SELECTION OF BASIC APPROACH . . . . . . . . . . . . . 4

4. 0 REACTOR MASS MODEL. . . . . . . . . . . . . . . 6

4.1 Solution Scheme . . . . . . . . . . . . 6

4.2 Fuel Mass . . . . . . . . . . . . . . . 6

4.2.1 Neutronic Limit... . . . . . . 6

- Burnup Requirement . . . . . . 6

- Initial Criticality . . . . . . . 7

- End-of-Life Critical Mass... . . 9

- Total U Mass to Reach End-of-Life. 10

4.2.2 Specific Power limit......... . 11

4.2.3 Burnup Fraction Limit........ 11

4.2.4 Limiting Uranium Mass . . . . . . 12

4.3 Moderator Mass............... . . . 12

4.4 Total Mass of the Fuel and Moderator. . . 12

4.5 Reactor structure Mass... . . . . . . 12

4.6 Total Core Mass . . . . . . . . . . . 13

4.7 Reflector Mass................ 14

4.8 Pressure Vessel Mass . . . . . . . . . 15

4.9 Miscellaneous Mass . . . . . . . . . . 16

4.10 Total Reactor Mass . . . . . . . . . . 16

5. 0 SHIELD MASS MODEL . . . . . . . . . . . . . . . 17

5.1 Neutron Shield Thickness. . . . . . . . . 17

5.2 Gamma Shield Thickness . . . . . . . . . 18

5.3 Neutron/Gamma Shield Thickness Iteration . . 20

5.4 Shield Mass Calculation . . . . . . . 20

6.0 PRELIMINARY INPUT DATA . . . . . . . . . . . . . 25 


$$
\text { CONTENTS (cont'd) }
$$

$\underline{\text { Paqe }}$

7.0 COMPARISON WITH DETAILED CALCULATIONS . . . . . . 29

8.0 STATUS, LiMITATIONS, AND FUTURE WORK . . . . . . 34

9.0 REFERENCES . . . . . . . . . . . . . . . . . 35

APPENDIX 1 . . . . . . . . . . . . . . . . . . . . . 37

APPENDIX 2 . . . . . . . . . . . . . . . . . . . 41

APPENDIX 3 . . . . . . . . . . . . . . . . . . . . . . 45

APPENDIX 4 . . . . . . . . . . . . . . . . . . . . . 47 


\section{LIST OF FIGURES}

Figure

Page

1

Critical Uranium Mass vs. Moderator-to-Fuel

Ratios for 93 Percent Enriched Fuel and

Various Moderators

RSMASS Assumed Shield Geometry . . . . . . 21

Liquid Metal Cooled Reactor/Shield . . . . 31

4

Thermionic Reactor/Shield . . . . . . . . 32

5

Gas Cooled Reactor . . . . . . . . . . 33

6 Geometry of Reactor/shield Assumed for Dose

Derivation . . . . . . . . . . . . . . . . 


\section{LIST OF TABLES}

$\underline{\text { Table }}$

$\underline{\text { Page }}$

1 RSMASS Input Data - Particle Bed Bimodal

$$
\text { Reactor } \mathrm{ZrH}_{1.7} \text {. . . . . . . . . . . . . . . } 26
$$

2 RSMASS Input Data - Liquid Metal Cooled

Reactor.................. . . 27

3 RSMASS Input Data - Conventional Thermionic

Reactor... . . . . . . . . . . . . . 28 


\section{ACKNOWLEDGMENTS}

The contributions of several individuals within the Advanced Power systems Division are acknowledged. J. Aragon programmed the RSMASS code and performed numerous calculations with this code during the model development effort. P. McDaniel and D. Gallup performed the transport theory neutronics calculations to obtain the compacted sphere critical mass data used in the RSMAss model. 
Blank Page 


\subsection{INTRODUCTION}

The Advanced Nuclear Power Systems Division at Sandia National Laboratories and the NASA Lewis Research Center provide technical assistance to the strategic Defense Initiative, space Power office's Independent Evaluation Group. Our responsibility includes the review of potential multimegawatt (MMW) space power systems to identify promising concepts and to determine the technologies that should be developed. Since launch costs are expected to be a major consideration for any space-based power system. reasonable estimates of the power system masses are essential to identify promising concepts and technologies. System codes are being developed at Sandia National Laboratories jointly with NASA Lewis Research center, which will allow rapid system mass estimates to be made for a variety of systems over a broad parameter space. Consequently, a simple reactor/ shield mass model (RSMASs) was developed to be used as a subroutine in the system codes for nuclear powered systems.

This document describes the reactor/shield mass model (RSMASS) that has been developed to provide mass estimations for reactors considered for multimegawat power systems for SDI applications. The technical basis for the approach, the status of the model, model limitations, and future work are also discussed. Detailed derivations are included in the appendices. 


\subsection{SOME PRECAUTIONARY COMMENTS}

RSMASS was developed to provide rapid estimates of reactor and shield masses for space power reactors. Our objective was to keep the RSMASs calculation time to a minimum so that it could be used as a subroutine in a systems code. This model is also useful for scoping and parameter studies. comparing the masses of different types of reactors, determining the dependence of reactor/shield mass on power level and duration of operation, and for making rough checks of the reactor/shield masses predicted by proposers of various space power reactor concepts. RSMASs does an excellent job of performing the above tasks and has far exceeded our design goals with respect to accuracy of results. However, in order to permit rapid estimates suitable for overall systems analyses. RSMASS uses a number of simplifying approximations. These approximations make RSMASS unsuitable as a design tool and it should not be considered as an alternative to detailed neutronics, and thermal hydraulics calculations and other detailed calculations required to make very accurate mass predictions.

Although the mass model has been validated by comparisons with more sophisticated calculations, some reactor concepts could possibly incorporate features that are not directly accounted for by RSMASS. In some cases reactor design experience will be reguired to identify and to account for these features. In other cases, the impact of these features will become apparent only after a comparison is made with more detailed calculations. If innovative reactor concepts proposed are significantly different from the ones explored to date. the RSMASS model and input parameters may require updating to adequately model these concepts.

It should also be recognized that the reactor parameters provided by reactor concept proposers may not be:

- optimized for low mass

- consistent or even possible

- desirable for safety or operational reasons

- practical or economically feasible.

Furthermore, the reactor parameters supplied by the proposers and the parameters provided in this document are very preliminary. 
Finally, care must be taken when drawing conclusions from the results obtained from any reactor mass model. For example, conclusions drawn from a mass study for a particular gas-cooled reactor should not be considered as representative or typical of all gas-cooled reactors. There is a wide variety of design choices: and since mass is not the only criterion for selection. the reactor masses may be very different for different design choices. Furthermore, a system mass analysis is required to determine the net impact of a reactor choice on the system mass. A concept with a low reactor mass may require a relatively heavy power conversion or radiator mass. resulting in a heavy system mass relative to other concepts.

If the precautions discussed above are observed, RSMASS should prove to be a valuable tool for providing good reactor/shield mass estimates. 


\subsection{SELECTION OF BASIC APPROACH}

A reactor/shield mass model is required to estimate the dependence of system mass on power and energy. Although this model was originally envisioned as a subroutine in a system code, a "stand-alone" version is also useful to permit quick power and energy parametric studies and to check mass estimates for specific proposed reactor systems. This model could also be used to compare different types of reactor systems and to explore sensitivities to changes in fuel type, temperature limits, and other parameters.

Since the model will be used for broad parametric studies. the code should require minimal input data and minimal setup and computational time and should permit variations in all important parameters. Although a code with these attributes must necessarily be simple. it must not be so simple that accuracy is substantially impaired. The code should also be transportable to other systems and should be useable by nonnuclear engineers and scientists (within the precautions noted in section 2.0).

As previously stated, nuclear reactors possess attributes that make these objectives difficult to achieve. Nuclear power systems offer a wide variety of designs. materials, and parameter choices. A particular design may be chosen because of its capability for high power densities, or high burnup. or desirable kinetics characteristics. etc. These design choices may not be optimized in terms of mass, and the mass penalty for these choices is not always obvious to either the proposer or a reviewer. On the other hand. the use of advanced materials and concepts may result in reactor masses much less than for "typical reactors." For these reasons, a large range in reactor masses is possible for various designs that are proposed to achieve the same power level. A mass model that is a function of only reactor power cannot accurately predict the masses for many reactor designs.

After considering the above facts it became clear that a simple correlation to obtain reactor/shield masses would be too crude for the intended purposes. On the other hand. very detailed calculations would require far too much time to be useful for parameter studies and for verification of mass calculations for many concepts.

Based on these conclusions, an intermediate modeling approach has been taken, which allows the mass to be computed as a function of important parameters. Values for these parameters will be eventually provided (by the author) 
for all reactor types of interest. Hence, once these parameters have been specified, the user is required to supply only the power and energy input data for these reactor types to determine the masses. If specific designs must be evaluated or if the dependence on a particular variable is desired, the model will allow these variables to be changed.

For the critical mass calculation, standard approximations. like the four-factor formula. could have been used. However, a more accurate model, which requires less user experience and less input data, was developed for RSMAsS. In this model the critical mass for compacted, reflected spheres is an input parameter and the critical mass of the reactor is obtained by correcting the compacted sphere mass for voids, heterogeneities, absorber materials, etc. The compacted sphere critical mass data has been obtained. from transport theory calculations as a function of the moderator to fuel ratio for several moderators. 


\subsection{REACTOR MASS MODEL}

\subsection{Solution Scheme}

The sequence used to compute reactor mass is to first compute the reactor fuel mass and then to compute the mass of all other reactor components. This approach is required since the mass of all other components is dependent on the fuel mass. The reactor fuel mass will be determined either by neutronic limits (burnup + criticality), specific power limits, or fuel burnup fraction limits--whichever yields the largest mass. The other components considered for this mass model include moderator. structure, reflector. pressure vessel, and miscellaneous components.

\subsection{Fuel Mass}

\subsubsection{Neutronic Limit}

\section{- Burnup Requirement}

In order to provide power over the life of the reactor. uranium-235 must be consumed. If we assume a deposited energy of $200 \mathrm{Mev} / \mathrm{f} i s s i o n$ and make appropriate adjustments for conversion of units. the mass of uranium required for fuel burnup is:

$$
M_{B}=\frac{0.38 E}{\varepsilon e}
$$

where $\quad M_{B}=U$ mass required for burnup (kg).

$E=$ Energy (MWe - years). [1]

$e=$ net fractional efficiency,[1] and

$\varepsilon=$ fractional fuel encichment. [1]

Note that the right-hand side of Equation (1) has been divided by $\varepsilon$ to convert from uranium-235 mass consumed to total uranium mass required for burnup. Also note that the electrical energy $E$ is divided by the net efficiency $e$ to determine the total thermal energy required. For some applications, it may be more convenient to replace $\mathrm{E} / \mathrm{e}$ by $\mathrm{E}_{\mathrm{th}}$. It should also be pointed out that Equation (1) does not include fission from plutonium-239 that has been produced from uranium-238. Although this latter consideration is probably not important for these reactor systems. this effect will be explored later. 
The critical uranium-235 mass (M\&) for compacted. reflected spheres is given in Figure 1 as a function of the moderator to uranium-235 molecular density ratio (R) for LiH. $\mathrm{ZrH}_{1}$.7. BeO, and graphite moderators. This data was obtained from transport theory computer calculations performed by $P$. McDaniel and $D$. Gallup using the FEMP code (Reference 18). In these calculations, full density $\left(13,600 \mathrm{~kg} / \mathrm{m}^{3}\right)$ UC fuel. 93 percent enriched in uranium-235, was assumed with a Beo reflector thickness equal to one-half the sphere radius. These calculations were checked using the TwODANT Code (Ref. 19). For unmoderated reactors, the critical mass is $28 \mathrm{~kg}$. For fully moderated (fully thermalized) reactors. uranium masses on the order of 1 or $2 \mathrm{~kg}$ can be obtained: however, for Beo and $C$ moderators, full moderation requires substantial moderator masses.

Power-producing reactors are not compacted spheres: other materials such as cladding. coolant. and structure occupy much of the reactor volume. Appendix 1 shows that the correction for the actual fuel volume fraction and fuel density is approximately:

$$
{ }_{C}^{C}\left(\frac{13,600}{V F \rho_{F}}\right)^{1.5}
$$

The correction for lower enrichments is shown in Appendix 2 to be approximately $1 / \varepsilon$. The $1 / \varepsilon$ correction is a reasonable approximation if the fuel enrichment is fairly high (>40\%) or if the reactor is not highly thermalized. For reactors that are both highly thermalized and low enrichment. resonance effects will need to be accounted for.

Other materials present in the core will either parasitically absorb or scatter neutrons: a correction $C_{M}$ must be applied to the critical mass to account for these effects. A method for obtaining these corrections ( $C_{M}$ ) will be discussed in a forthcoming document. At present a guess is used for $C_{M}$ (usually 1.0 ). This correction may also be used to correct for heterogeneities and for resonance capture for moderated low enrichment cores. The effects of fission product absorption and temperature defect on the critical mass requirement will be ignored for the reasons given in Appendix 3.

If the calculated $\mathrm{U}^{235}$ critical mass is then divided again by the enrichment to get the total uranium mass, then the formula for the initial uranium critical mass is: 


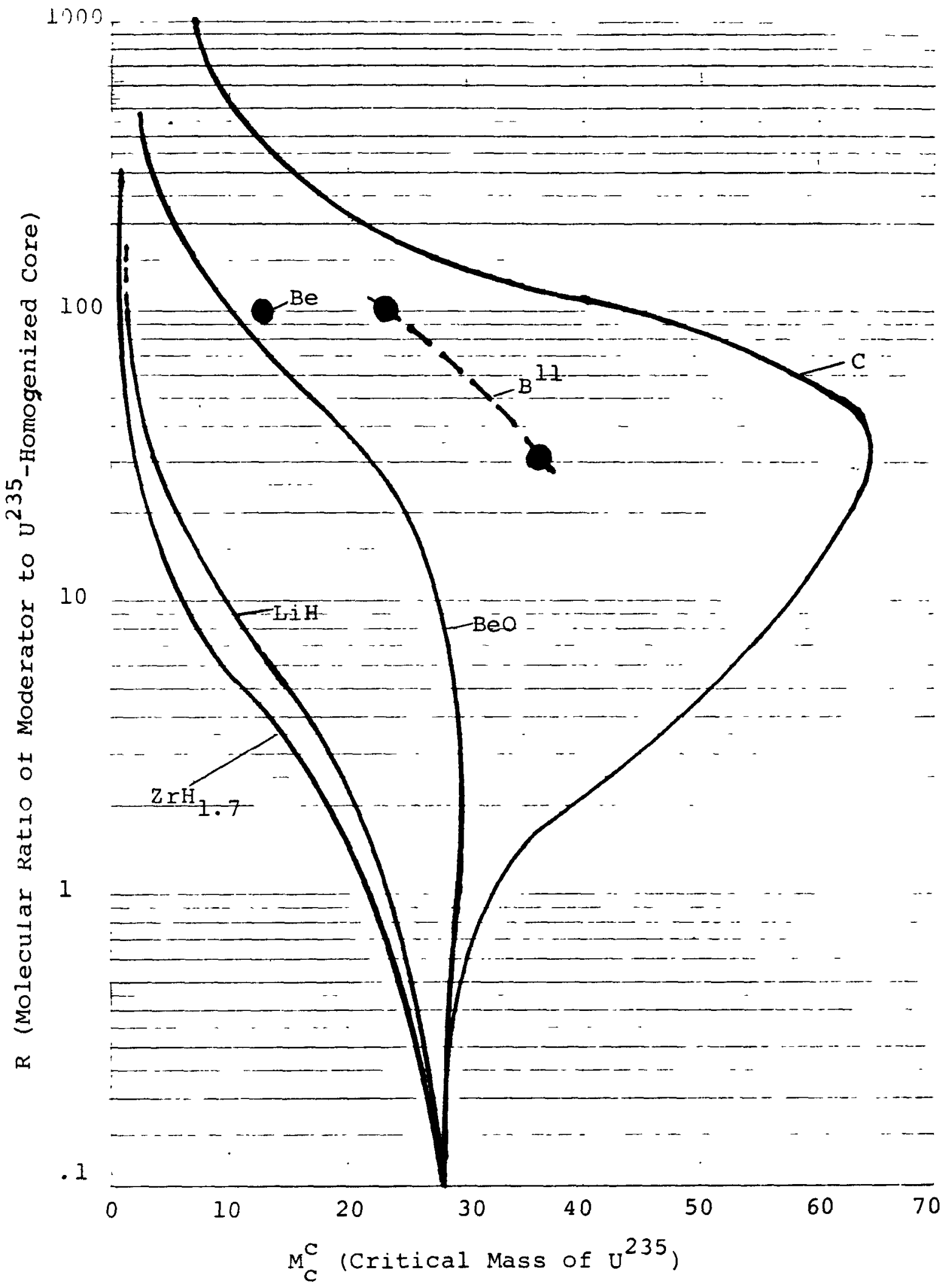

Figure 1. Critical Uranium Mass vs. Moderator-to-Fuel Ratios for 93 Percent Enriched Fuel and Various Moderators. A BeO Reflector (Thickness $=1 / 2$ Core Radius) and UC fuel assumed for all moderators. 


$$
M_{C}^{0}=\frac{C_{M} M_{C}^{C}}{\varepsilon^{2}}\left(\frac{13,600}{V F \rho_{F}}\right)^{1.5}
$$

where $\quad M_{C}^{0}=$ initial critical $U$ mass $(\mathrm{kg})$. $\begin{aligned} M_{C}^{C}= & \text { critical mass for compact reflected UC sphere } \\ & \left(k g \text { of } \mathrm{U}^{235}\right),[1]\end{aligned}$

$C_{M}=$ correction factor for absorbers and for coolant scattering, [1]

$V F=$ fuel volume fraction of core.[1] and

$\rho_{\mathrm{F}}=$ unhomogenized fuel density $\left(\mathrm{kg} / \mathrm{m}^{3}\right) .[1]$

It should be pointed out that these critical mass estimates do not account for neutron leakage through large leakage paths (e.g.. large central cavity) that may be present in some reactor concepts.

\section{- End-of-Life Critical Mass}

Since some of the original uranium-235 will burn up during reactor operation, the end-of-life enrichment will be lower than the beginning-of-life enrichment. We can define an effective end-of-life enrichment $\left(\varepsilon_{E}\right)$ as:

$$
\varepsilon_{E} \equiv \frac{{ }^{\varepsilon M} C}{M_{C}+{ }_{B}(1-\varepsilon)} \equiv \frac{\text { Mass of } U^{235} \text { at end of life }}{\text { Total U mass at end of life }}
$$

where $M_{C}=$ end-of-life critical uranium mass (kg) and

$$
M_{B}=\text { uranium mass required for burnup. }
$$

This just says that when the uranium-235 required for burnup $\left(\varepsilon M_{B}\right)$ is used up. the amount of uranium-235 remaining is just the mass required for criticality $\left(\varepsilon M_{C}\right)$, while the total uranium left in the core will be the uranium required for criticality ( $\left.\mathbf{M}_{C}\right)$ plus the uranium-238 associated with the fuel for burnup $\left[\mathcal{M}_{B}(1-\varepsilon)\right]$ : consequently, the enrichment will be reduced at end-of-life. Accounting for the lower end-of-life enrichment the required uranium-235 is: 


$$
\frac{-C_{M}{ }_{M}^{C}}{\varepsilon_{E}}\left(\frac{13,600}{V F \rho_{f}}\right)^{1.5}
$$

If we divide again by $\varepsilon$ to get the total uranium required. then from Equation ( 2 ) we have:

$$
M_{C}=M_{C}^{0} \frac{\varepsilon}{\varepsilon_{E}}
$$

Substituting in the terms for $\varepsilon_{E}$. from its definition. into the above equation, a quadratic equation is obtained with the solution:

$$
M_{C}=\frac{M_{C}^{0}+\sqrt{M_{C}^{0}+4 M_{C}^{M_{B}}(1-\varepsilon)}}{2}
$$

Knowing $M_{C}$ we can now solve for the other unknown ( $\varepsilon_{\mathrm{E}}$ ) from its definition:

$$
\varepsilon_{E}=\frac{\varepsilon M_{C}}{M_{C}+M_{B}(1-\varepsilon)} .
$$

(The value for $\varepsilon_{\mathrm{E}}$ is not required for the mass calculation: however. the value of $\varepsilon_{\mathrm{E}}$ is often of interest and is. therefore, calculated by RSMÁSS.)

- Total U Mass to Reach End-of-Life

The total U mass required to achieve criticality throughout the life of the reactor is just the sum of the uranium required for burnup and the uranium required for criticality at end-of-life.

$$
M_{E}=M_{C}+M_{B}
$$

where $M_{E}=$ total $U$ mass required based on neutronic limits $(\mathrm{kg})$.

This is the uranium mass required based on neutronic limits. 


\subsubsection{Specific Power Limit}

Although very large quantities of power can be obtained from small quantities of uranium, heat transfer from the fuel to the coolant and temperature limits on the fuel. cladding. and coolant will place a limit on the specific power for a reactor. This limit will depend on the fuel, geometry, coolant, etc. The mass of uranium required based on specific power limits is:

$$
{ }^{M_{P}}=\frac{{ }^{P P_{F}}}{{ }_{{ }_{S}}{ }^{\mathrm{e}}}
$$

where $\quad M_{P}=U$ mass required based on specific power limits $(\mathrm{kg})$.

$$
P=\text { maximum reactor power (MWe), [1] }
$$

$P_{F}=$ core spatial peak/avg. power factor. [1]

$P_{S}=$ specific power limit $\left(\mathbf{M W}_{\mathrm{th}} / \mathrm{kg} \mathrm{U}\right),[1]$ and

e $=$ net efficiency.[1]

In the present version of RSMASS. PS must be computed based on heat transfer calculations and temperature limits and then entered as an input parameter and this approach is a bit cumbersome. At a later date a thermal/hydraulic model may be built into the code to permit mass calculations directly from temperature limits.

\subsubsection{Burnup Fraction Limit}

Although there may be adequate fuel present to provide the needed energy for a reactor, there will normally be a limit placed on the fraction of fuel that can be burned up. This limit is based on fuel damage and gas release considerations for a particular design and operating conditions. For a maximum permitted burnup fraction of $B$. the average burnup fraction is $\beta / P_{F}$, and from Eg. (1) we know that the mass of uranium that is burned up is $0.38 \mathrm{E} / \mathrm{e}$ : consequently, the mass of uranium required based on burnup fraction limits is:

$$
M_{F}=\frac{0.38 \mathrm{EP}_{\mathrm{F}}}{\beta e}
$$

where $\quad M_{F}=U$ mass required based on burnup fraction limit $(\mathrm{kg})$, and 
$\beta=$ maximum permitted uranium burnup fraction. [1] (Atoms of uranium fissioned per $\mathrm{cm}^{3} /$ total number of initial uranium atoms per $\mathrm{cm}^{3}$.)

\subsubsection{Limiting Uranium Mass}

The mass of uranium required for any reactor system will be the largest of the three masses based on the three potential limits: i.e..

$$
M_{L}=\text { greatest of } M_{E} \cdot M_{P} \text {, and } M_{F} \text {. }
$$

\section{3 Moderator Mass}

If a moderator is present in the reactor, the moderator mass can be computed using the formula for the molecular density: i.e.:

$$
\text { molecular density }=\frac{\text { Mass }}{\text { Vol. }} \times \frac{\text { Avogadro's Number }}{\text { Molecular Weight }} \text {. }
$$

Using this formula and the definition of $R$, the mass of the moderator is determined to be:

$$
M_{M}=\varepsilon M_{L} R\left(\frac{M W_{M}}{235}\right)
$$

where $\quad M_{M}=$ moderator mass $(\mathrm{kg})$.

$$
\begin{aligned}
R= & \text { ratio of the homogenized molecular density of } \\
& \text { the moderator to U-235, [1] and } \\
\mathbf{M W}_{M}= & \text { moderator molecular weight. [1] }
\end{aligned}
$$

\section{4 Total Mass of the Fuel and Moderator}

$$
M_{T}=M_{L}+M_{M}
$$

\subsection{Reactor Structure Mass}

In addition to the fuel and moderator, the reactor core will contain a coolant and a number of structural components. such as cladding. grid spacers, cermet parent material. support structure. etc. In this analysis, the coolant mass will be assumed to be accounted for in the balance of plant. 
The easiest approach for estimating the structural mass is to assume all of the structure can be represented by one material of density $\rho_{S}$. Knowing the fuel volume and the moderator volume and the approximate ratio of the structural volume to the fuel-plus-moderator volume, the structural mass can then be computed. Hence, the following steps are used to compute the structural mass:

$$
\begin{aligned}
& \rho_{\mathrm{T}}=\frac{{ }_{\mathrm{T}}}{\left(\frac{\mathrm{M}_{\mathrm{L}}}{\rho_{\mathrm{F}}}+\frac{{ }_{\mathrm{M}}}{\rho_{\mathrm{M}}}\right)} \\
& \mathrm{M}_{\mathrm{S}}=\rho_{\mathrm{S}} \mathrm{R}_{\mathrm{V}} \frac{\mathrm{M}_{\mathrm{T}}}{\rho_{\mathrm{T}}}
\end{aligned}
$$

where $\quad \rho_{\mathrm{T}}=$ fuel-plus-moderator homogenized density $\left(\mathrm{kg} / \mathrm{m}^{3}\right)$.

$$
\begin{aligned}
& \rho_{M}=\text { moderator density }\left(\mathrm{kg} / \mathrm{m}^{3}\right),[1] \\
& \rho_{F}=\text { fuel density, [l] } \\
& R_{V}=\begin{array}{l}
\text { ratio of structure volume to fuel-plus- } \\
\text { moderator volume.[l] }
\end{array} \\
& M_{S}=\text { mass of core structure }(\mathrm{kg}) . \text { and } \\
& \rho_{S}=\text { average structural density }\left(\mathrm{kg} / \mathrm{m}^{3}\right) .[1]
\end{aligned}
$$

Initially. $R_{V}$ is an estimate based on judgement and reactor design experience. As the design progresses and better information becomes available, better estimates for RV will be obtained.

\subsection{Total Core Mass}

The total core mass is then:

$$
\mathbf{M}_{\mathrm{TC}}=\mathbf{M}_{\mathrm{T}}+\mathbf{M}_{\mathrm{S}}
$$

where $\quad M_{T C}=$ total core mass $(\mathrm{kg})$. 


\subsection{Reflector Mass}

To simplify the solution, the core and reflector will be approximated by a sphere and shell, respectively. Therefore. the core volume is:

$$
V_{C}=\frac{M_{T}}{V F \rho_{T}}
$$

where $V_{C}=$ core volume $\left(\mathrm{m}^{3}\right)$ and the core radius is given by:

$$
r=\left(\frac{3}{4} \frac{V_{C}}{\pi}\right)^{1 / 3}
$$

where $r=$ core radius $(m)$.

The reflector thickness can be assumed to be some fraction of the core radius.

$$
T=F_{r} r
$$

where $\quad T=$ reflector thickness $(m)$ and

$$
F_{r}=\text { fraction of core radius. [1] }
$$

Although Equation (16) is a reasonable approximation over most ranges. the reflector thickness for very small and very large reactors may be too small or too large, respectively: consequently, minimum and maximum reflector thicknesses may be specified as input parameters. Also, when the code is used to check the mass predictions for reactors with a typical reflector thickness. it may be desirable to fix the reflector thickness at some prespecified value. The following procedure allows for these options:

$$
\text { If } \begin{aligned}
T \leq T_{\min }: & T=T_{\min } \\
T \geq T_{\max }: & T=T_{\max } \\
T_{f i x}>0: & T=T_{f i x}
\end{aligned}
$$


where $\quad T_{\min }=$ minimum reflector thickness $(\mathrm{m})$. [1]

$$
\begin{aligned}
& \mathrm{T}_{\max }=\text { maximum reflector thickness }(\mathrm{m}) .[1] \text { and } \\
& \mathrm{T}_{\mathrm{fix}}=\text { fixed reflector thickness }(\mathrm{m}) .[1]
\end{aligned}
$$

Knowing the reflector thickness, the reflector mass can be approximated by:

$$
M_{R F}=4 \pi r^{2} T \rho_{R F}
$$

where $M_{R F}=$ reflector mass $(\mathrm{kg})$ and

$$
\rho_{\mathrm{RF}}=\text { reflector density }\left(\mathrm{kg} / \mathrm{m}^{3}\right) .[1]
$$

\subsection{Pressure Vessel Mass}

The pressure vessel may be located inside or outside the reflectors: consequently, the pressure vessel radius will be given by:

$$
r_{P V}=r+n T
$$

where

$$
\begin{aligned}
\mathrm{r}_{\mathrm{PV}} & =\text { pressure vessel radius }(\mathrm{m}) \\
\mathrm{n} & =0 \text { :pressure vessel inside reflector.[1] and } \\
\mathrm{n} & =1 \text { :pressure vessel outside reflector.[1] }
\end{aligned}
$$

The pressure vessel may be approximated by a cylinder of radius $\mathrm{r}_{\mathrm{PV}}$ and height $2 \mathrm{r}_{\mathrm{PV}}$ with hemispherical ends. The space within the hemispherical ends of the pressure vessel includes the coolant plenum space, end fittings, etc. If the vessel is assumed to have a uniform wall thickness. the minimum wall thickness based on stress considerations is approximately:

$$
\tau \approx \frac{3}{4} \frac{{ }_{r} r_{P V}}{U_{S}}
$$


where $t=$ pressure vessel thickness $(m)$.

$$
\begin{aligned}
P_{\mathbf{I}} & =\text { max coolant pressure (MPa), [1] } \\
\mathbf{S} & =\text { factor of safety, and } \\
U_{S} & =\text { ultimate strength of pressure vessel }
\end{aligned}
$$

The pressure vessel volume is approximated by $8 \pi r_{P V}^{2}$. Then assuming a factor of safety of 4.0 for reactor pressure vessels, the pressure vessel mass is given by:

$$
M_{\mathrm{PV}}=24 \pi r_{\mathrm{PV}}^{3} \frac{\mathrm{P}_{\mathrm{r}}}{\mathrm{U}_{\mathrm{S}}} \rho_{\mathrm{PV}}
$$

where $\quad M_{P V}=$ pressure vessel mass $(\mathrm{kg})$ and

$$
\rho_{\mathrm{PV}}=\text { pressure vessel density }\left(\mathrm{kg} / \mathrm{m}^{3}\right) \cdot[1]
$$

\subsection{Miscellaneous Mass}

Control drives and actuators, instrumentation, safety features. and a number of other miscellaneous components were not explicitly accounted for in the previous computations. The mass of these miscellaneous components will be assumed to be some fraction (F) of the fuel-plus-moderator mass $\left(M_{T}\right)$. Thus:

$$
\mathrm{M}_{\text {MIS }}=\mathrm{FM}_{\mathrm{T}}
$$

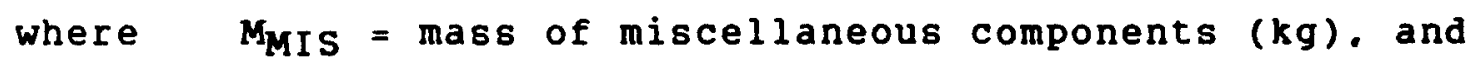

$$
\begin{aligned}
F= & \text { multiplier of fuel-plus-moderator mass to } \\
& \text { obtain miscellaneous mass.[1] }
\end{aligned}
$$

\subsection{Total Reactor Mass} masses.

The total reactor mass is the sum of all the component

$$
\mathbf{M}_{\mathrm{R}}=\mathbf{M}_{\mathrm{TC}}+\mathbf{M}_{\mathrm{RF}}+\mathbf{M}_{\mathrm{PV}}+\mathbf{M}_{\mathrm{MIS}}
$$




\subsection{SHIELD MASS MODEL}

\subsection{Neutron Shield Thickness}

It is shown in Appendix 4 that the dose at the payload from a shielded reactor can be approximated by the generalized equation:

$$
D_{R}=\frac{\operatorname{CEexp}(-\mu t)}{\mu_{C} r e R_{P}^{2}}
$$

where $\quad C=$ normalization constant.

$$
\mu=\text { generalized shielding coefficient }\left(\mathrm{cm}^{-1}\right) \text {. }
$$$$
R_{P}=\text { the distance from the reactor to the pay- }
$$
load (m).

$\mu_{C}=$ generalized self-absorption coefficient for the core $\left(\mathrm{cm}^{-1}\right)$.

$r=$ core radius $(m)$, and

$t=$ shield thickness (m).

The normalization constant was obtained from a detailed Monte Carlo calculation (Reference 1). For neutron shielding $\mu$ is more commonly represented by the macroscopic removal cross section $\Sigma_{R}$, and $\mu_{C}$ is more commonly represented by $\Sigma_{C}$. Using these terms and the value for $C$ given in Appendix 4 , the required shield thickness is given by:

$$
t_{n}=\frac{-\ln \left[\frac{\left(1.5 \times 10^{-17}\right) D_{n} r R_{P}^{2} \Sigma_{c} e}{E}\right]}{100 \Sigma_{r}}
$$

$\left(\right.$ for $\left.t_{n} \leq 0: \quad t_{n}=0\right)$.

Here. $\quad t_{n}=$ initial neutron shield thickness (m).

$$
\begin{aligned}
E & =\text { energy (MWe } \cdot \text { years) }[1] \\
D_{n} & =\text { max allowed payload neutron dose (nvt). } \\
e & =\text { net fractional efficiency, [1] }
\end{aligned}
$$




$$
\begin{aligned}
-R_{p}= & \text { payload separation distance }(m),[1] \\
\Sigma_{C}= & \begin{array}{l}
\text { core macroscopic self-absorption cross section } \\
(\mathrm{cm}-1) .[1] \text { and }
\end{array} \\
\Sigma_{r}= & \begin{array}{l}
\text { shield macroscopic neutron removal cross section } \\
\left(\mathrm{cm}^{-1}\right) .[1]
\end{array}
\end{aligned}
$$

This assumes that no neutrons are absorbed by the gamma shield.

\subsection{Gamma Shield Thickness}

Since the neutron shield will also attenuate gammas, the neutron shield-gamma attenuation $\left(\mu_{n} t_{n}\right)$ must first be subtracted out. The required gamma shield thickness is then given by:

$$
t_{Y, 0}=\left(\frac{-1}{\mu_{Y}}\right)\left(\frac{\ln \left[\frac{D_{Y} \mu_{c} r R_{P}^{2}\left(1.0 \times 10^{-9}\right) e}{E}\right]}{100}+\mu_{n} t_{n}\right)
$$

$($ for $t \gamma .0<0: \quad t \gamma .0=0)$.

where

$$
\begin{aligned}
& t_{Y, O}=\text { first iteration gamma shield thickness (m). } \\
& \mu_{\gamma}=\underset{(c m-1)}{\operatorname{gamma}} \text { shield } \quad \text { r-attenuation coefficient } \\
& \mu_{\mathrm{n}}=\underset{(\mathrm{cm}-1) .[1]}{\text { neutron }} \text { shield } r \text {-attenuation coefficient } \\
& \mu_{c}=\underset{\text { and }}{\text { core }} \gamma \text {-attenuation coefficient }\left(\mathrm{cm}^{-1}\right),[1] \\
& D_{Y}=\max \text { allowed payload gamma dose (R).[1] }
\end{aligned}
$$

For this calculation it is assumed that a single energy group can be used to estimate the attenuation of gammas for all energies. A preliminary comparison with detailed calculations suggests that attenuation coefficients for $3 \mathrm{MeV}$ gammas is a fair approximation as long as the gamma spectrum from the core and the spectral dependence of the gamma shield attenuation coefficient is not appreciably different from the values used in the normalization calculation (see Appendix 4).

Also, for the derivation of Equation (25) it was assumed that any gamma photon colliding with the shield material 
will not reach the payload. For thick shields, however. multiple collisions can scatter a fraction of the photons back to payload, building up the dose at the payload. This dose buildup can be accounted for by first computing the total gamma optical thickness of the shield as:

$$
\mu t_{t, 0}=\left(\mu_{n} t_{n}+\mu_{\gamma} t_{\gamma .0}\right) 100
$$

and then computing the buildup factor (Reference 2 ):

$B_{0}(\mu, t)=A_{1} \exp \left(-a_{1} \mu t_{t, 0}\right)+\left(1-A_{1}\right) \exp \left(-a_{2} \mu t t_{, 0}\right)$

where

$$
\begin{aligned}
\mathrm{B}_{0}(\mu, t)= & \text { gamma dose buildup factor, and } \\
\mathrm{A}_{1} \cdot \mathrm{a}_{1} \cdot \mathrm{a}_{2}= & \text { known buildup factor constants[1] } \\
& (\mathrm{e} . \mathrm{g} . . \text { Reference } 2) .
\end{aligned}
$$

The buildup factor is then inserted back into the gamma shield thickness calculation and iterated on to determine the final gamma shield thickness. The iteration procedure is as follows:

$$
\ell=1
$$

$$
\begin{aligned}
& t_{Y, \ell}=-\left(\frac{1}{\mu_{Y}}\right)\left(\frac{\ln \left[\frac{D_{Y} \mu_{c} r R_{p}^{2}\left(1.0 \times 10^{-9}\right) e}{B_{\ell-1}(\mu, t) E}\right]}{100}+\mu_{n} t_{n}\right) \\
& \mu t_{t, \ell}=\left(\mu_{n} t_{n}+\mu_{\gamma} t_{\gamma, \ell}\right) 100 \\
& B_{\ell}(\mu, t)=A_{1} \exp \left(-a_{1} \mu t_{t, l}\right)+\left(1-A_{1}\right) \exp \left(-a_{2} \mu t t_{1}\right) \text {. } \\
& \text { If }: \frac{t_{\gamma, l-1}}{t_{\gamma, \ell}}>1.05 \text { or }<0.95 \text {. } \\
& \ell=\ell+1 \text {, and return to (29). }
\end{aligned}
$$




\subsection{Neutron/Gamma Shield Thickness Iteration}

Now that the gamma shield thickness has been computed. we can now recalculate the neutron shield thickness accounting for the neutron shielding by the gamma shield:

$$
t_{n}^{\prime}=t_{n}-\frac{\Sigma_{r}^{\gamma} t_{\gamma}}{\Sigma_{r}}
$$

where $t_{n}^{\prime}=$ interim neutron shield thickness.

$$
\begin{aligned}
\Sigma_{r}= & \begin{array}{l}
\text { neutron removal cross section of the gamma } \\
\text { shield }\left(\mathrm{cm}^{-1}\right) .[1]
\end{array} \\
\Sigma_{\mathrm{r}}= & \begin{array}{l}
\text { neutron removal cross section of the neutron } \\
\text { shield }\left(\mathrm{cm}^{-1}\right) .[1] \text { and }
\end{array} \\
\mathrm{t}_{\gamma}= & \begin{array}{l}
\text { gamma shield thickness for the last iteration } \\
\text { of Equation }(29) .
\end{array}
\end{aligned}
$$

since the new neutron shield thickness is smaller than the original $t_{n}$. the gamma shield thickness must be recalculated to account for the reduced gamma-shielding by the neutron shield.

$$
t_{\gamma}^{*}=t_{\gamma}+\frac{\mu_{n}}{\mu_{\gamma}}\left(t_{n}-t_{n}^{\prime}\right)
$$

where $t_{\gamma}^{\star}=$ final gamma shield thickness $(m)$.

Finally. the new gamma shield thickness is used to compute the final neutron shield thickness.

$$
t_{n}^{*}=t_{n}-\frac{\Sigma^{\gamma}}{\Sigma_{r}} t_{\gamma}^{*}
$$

\subsection{Shield Mass Calculation}

The assumed shadow shield geometry for this model is presented in Figure 2. Two gamma shields and two neutron shields are permitted, and the user may specify the fractional split of the thickness between the first and second gamma shield and between the first and second neutron shield.

The distance from the far end of the reactor to the first gamma shield is given by: 


\section{RSMASS ASSUMED SHIELD GEOMETRY}

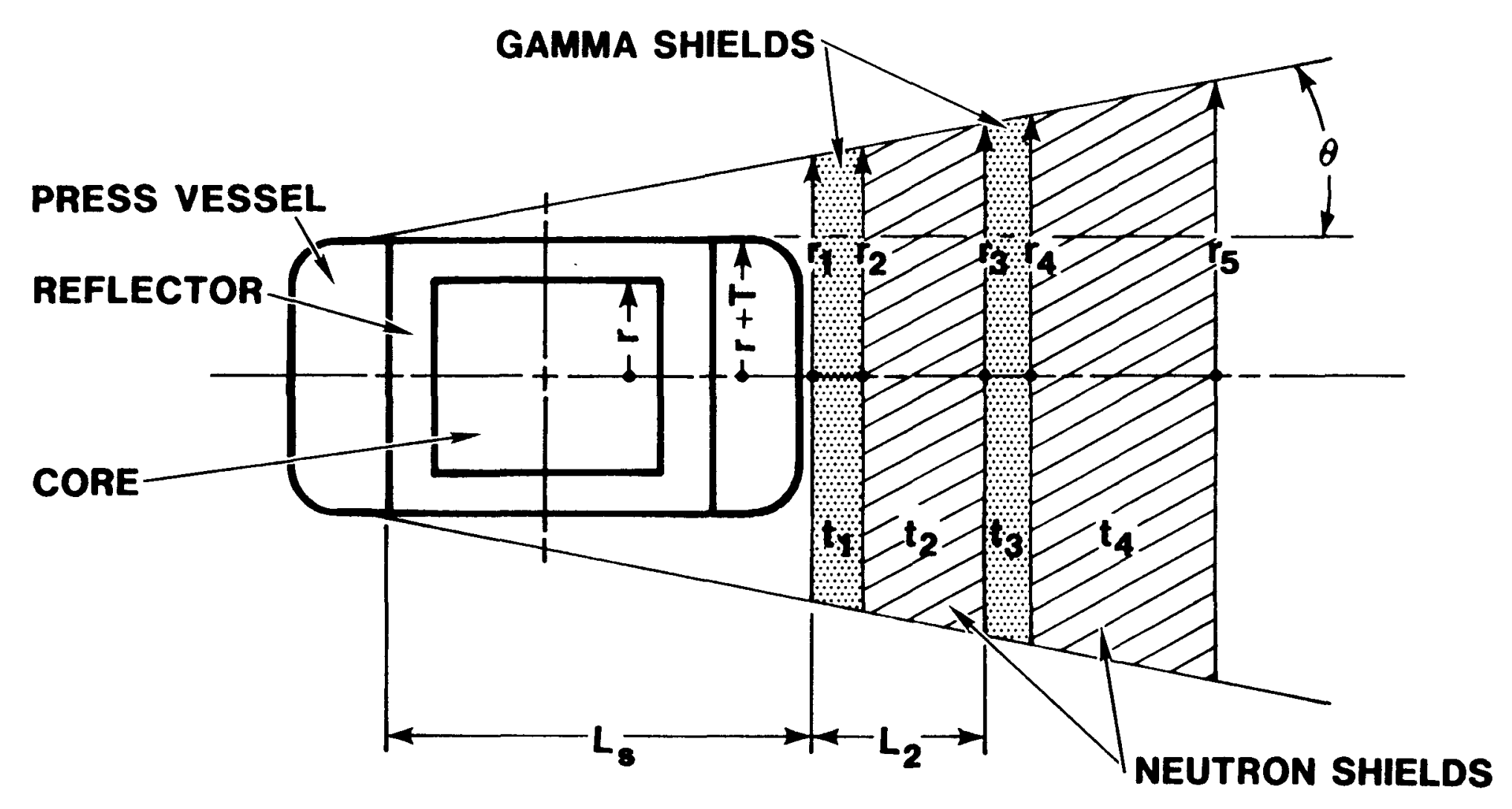

Figure 2. RSMASS Assumed Shield Geometry 


$$
L_{s}=F_{s} r
$$

where $L_{S}=$ distance to first gamma shield (m), and

$F_{S}=$ (multiplier on core radius to get $\left.L_{S}\right)$. [1]

The thickness of the first gamma shield is:

$$
t_{1}=F_{g} t_{\gamma}^{*}
$$

where $t_{1}=$ first gamma shield thickness (m) and

$$
\begin{aligned}
F_{g}= & \text { fraction of total gamma shield thickness used } \\
& \text { in first gamma shield.[1] }
\end{aligned}
$$

and the first neutron shield thickness is

$$
t_{2}=F_{n} t_{n}^{*}
$$

where $t_{2}=$ first neutron shield thickness (m), and

$$
\begin{aligned}
& F_{n}= \text { fraction of total neutron shield thickness } \\
& \text { used in first neutron shield. [1] }
\end{aligned}
$$

The distance to the second neutron shield $\left(L_{2}\right)$ is then:

$$
L_{2}=t_{1}+t_{2}
$$

and the thicknesses of the second gamma shield and second neutron shield are:

$$
t_{3}=t_{\gamma}^{*}\left(1-F_{g}\right)
$$

and

$$
t_{4}=t_{n}^{*}\left(1-F_{n}\right)
$$


where $t_{3}=$ thickness of second gamma shield (m) and

$$
t_{4}=\text { thickness of second neutron shield }(\mathbb{m}) \text {. }
$$

Since the total reactor radius $\left(r_{r}\right)$ given by:

$$
r_{r}=r+T
$$

where $\quad r=$ core radius and

$$
T=\text { reflector thickness. }
$$

we can compute radii $r_{1}$ through $r_{5}$ in Figure 2 as

$$
\begin{aligned}
& r_{1}=r_{r}+L_{s} \operatorname{Tan} \theta \\
& r_{2}=r_{r}+\left(L_{s}+t_{1}\right) \operatorname{Tan} \theta \\
& r_{3}=r_{r}+\left(L_{s}+L_{2}\right) \operatorname{Tan} \theta \\
& r_{4}=r_{r}+\left(L_{s}+L_{2}+t_{3}\right) \operatorname{Tan} \theta \\
& r_{5}=r_{r}+\left(L_{s}+t_{n}^{*}+t_{\gamma}^{\star}\right) \operatorname{Tan} \theta
\end{aligned}
$$

where $\theta=$ cone half angle (degrees). [1]

Using the equation for the frustrum of a cone and multiplying by the neutron and gamma shield densities, we can compute the shield mass

$$
\begin{aligned}
& M_{\gamma s}=\frac{G_{q} \rho_{s} \pi}{3}\left[t_{1}\left(r_{1}^{2}+r_{1} r_{2}+r_{2}^{2}\right)+t_{3}\left(r_{3}^{2}+r_{3} r_{4}+r_{4}^{2}\right)\right] \\
& M_{n s}=\frac{G_{n} \rho_{n s} \pi}{3}\left[t_{2}\left(r_{2}^{2}+r_{2} r_{3}+r_{3}^{2}\right)+t_{4}\left(r_{4}^{2}+r_{4} r_{5}+r_{5}^{2}\right)\right] \\
& M_{T S}=M_{n s}+M_{\gamma s}
\end{aligned}
$$


where $M_{Y S}=$ mass of gamma shield (kg).

$$
\begin{aligned}
M_{\mathrm{nS}}= & \text { mass of neutron shield }(\mathrm{kg}) . \\
M_{\mathrm{TS}}= & \text { total mass of shield }(\mathrm{kg}) . \\
\rho_{Y S}= & \text { gamma shield density }\left(\mathrm{kg} / \mathrm{m}^{3}\right),[1] \\
\rho_{\mathrm{nS}}= & \text { neutron shield density }\left(\mathrm{kg} / \mathrm{m}^{3}\right),[\mathrm{l}] \\
\mathrm{G}_{\mathrm{g}}= & \text { geometry correction factor for gamma } \\
& \text { shield. }[1] \text { and } \\
G_{\mathrm{n}}= & \text { geometry correction factor for neutron } \\
& \text { shield.[1] }
\end{aligned}
$$

The geometry correction factors, $G_{g}$ and $G_{n}$. allow for deviations from the assumed shadow shield geometry, including $2 \pi, 4 \pi$, shaped $4 \pi$ shields, etc.

The final reactor plus shield mass $\left(M_{R+S}\right)$ is then:

$$
M_{R+S}=M_{R}+M_{T S}
$$




\subsection{PRELIMINARY INPUT DATA}

Preliminary input data is provided in Tables 1, 2, and 3 for a gas-cooled, $2 \mathrm{rH}_{1} .7$ moderated particle bed reactor. a liquid-metal-cooled fast reactor, and for a thermionic reactor. respectively. The input data for these systems should be regarded as very preliminary and the uncertainty in the values for some of these parameters (particularly for the gas-cooled reactor) may be substantial. This parameter list will be updated by the author as concepts are refined and better data becomes available. 
Table 1

REACTOR: Part1cle Bed BLmodal $\mathrm{ZrH}_{1.7}$

$\frac{\text { Parameter }}{\text { Reactor }}$

\section{1. - efficiency}

2. c - enrichment

3. $R-\bmod$ rat lo

4. $m_{c}^{c}$ - compact crit. mass (kg)

5. vP - fuel t mod. vol. frac.

6. $p_{P}$ - fuel dens. $\left(\mathrm{kg} / \mathrm{m}^{3}\right)$

7. $C_{m}$ - crit. mass correc.

B. B - burnup 11m1t

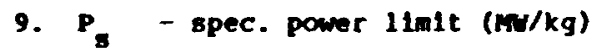

10. $P_{P}$ - peak/avg. power

11. M - mod. mol. wt. (g)

12. $P_{\mathrm{m}}-\bmod$. dens. $\left(\mathrm{kg} / \mathrm{m}^{3}\right)$

13. $R_{v}$ - struc.ffuel + mod. volume

14. $P_{g}$ - struc. dens. $\left(\mathrm{kg} / \mathrm{m}^{3}\right)$

15. $F_{r}$ - reflec. frac. of $r$

16. $T_{m i n}-m i n$. ref. $T(m)$

17. $T_{\max }-\max$. ref. $T(m)$

18. $T_{f 1 x}-f 1 x I(a)$

19. $P_{r f}$ - ref 1 . dens $\left(\mathrm{kg} / \mathrm{m}^{3}\right)$

20. $n$-press. vess. locator

21. U - press. vess. (MPa) strength

22. $p_{p v}$ - press. vess. dens. $\left(\mathrm{kg} / \mathrm{m}^{3}\right)$

23. $P_{r}$ - coolant press. (MPa)

24. P - M1s. Mass Praction
RSwass Input Data

(Burst) Alternate

0.19

$$
0.7
$$

70

1

0.7

13,000

1.6

0.50

20

1.3

93

5,610

0.35

10.600

0.5

0.05

0.20

0

1,700

1

1.360

8,000

13.6
DATR: 2/25/86

(Burst) (steady state) Parameter

25. $D_{n}$ - n-shleld dose limit (nrt)

26. $D_{Y}-Y$-dose linit (R)

27. Rp - payload distance (m)

28. $I_{c}$ - core renov. $x-\sec \left(\mathrm{cm}^{-1}\right)$

29. $u_{c}$ - core $x$-atten. $x-\sec \left(\mathrm{cm}^{-1}\right)$

30. $I_{r}$ - shield n-removal $x-\sec \left(\mathrm{cm}^{-1}\right)$

31. $\sum_{r}^{r}-Y$-shleld $n$-renoval $x-\sec \left(\mathrm{cm}^{-1}\right)$

32. $\mu_{n}-n$-shield $Y$-atten. $x-\sec \left(\mathrm{cm}^{-1}\right)$

33. ${ }_{Y}-Y$-shield $Y$-atten $x$-sec $\left(\mathrm{cs}^{-1}\right)$

34. $\theta$ - cone $1 / 2$ angle (deg.)

35. $P_{n s}-n$-shield dens. $\left(\mathrm{kg} / \mathrm{m}^{3}\right)$

36. $P_{Y s}-Y$-shield dens. $\left(\mathrm{kg} / \mathrm{m}^{3}\right)$

37. $A_{1}$

38. $\left.a_{1}\right\}$

39. $a_{2}$

40. $F_{s}-$ mult. on $r$ for $t_{s}$

11. $P_{n}$ - wult. on $t_{n}$ for $t_{2}$

12. $F_{g}-$ wult. on $t_{g}$ for $t_{1}$

43. O - gecenet. correction for $Y$-shteld

14. $o_{n}^{g}$ - geomet. correc. for n-shield value

Alternate 
Table 2

ReActor: Liquid metal cooled

$\frac{\text { Parameter }}{\text { Reactor }}$

2. - enrichnent

3. $R-\bmod$ rat 10

4. $M_{C}^{C}$ - compact crit. mass (kg)

5. VP - fuel + mod. vol. frac.

6. $p_{p}$ - fuel dens. $\left(\mathrm{kg} / \mathrm{m}^{3}\right)$

7. $c_{\text {m - crit. mass correc. }}$

8. B - burnup $1 \mathrm{Imit}$

9. P - spec. power limit (m/kg)

10. P - peak/avg. power

11. M. - mod. mol. wt. (g)

12. $P_{m}-\bmod$. dens. $\left(\mathrm{kg} / \mathrm{m}^{3}\right)$

13. $R_{v}$ - struc./fuel + mod. volume

14. $p_{8}$ - struc. dens. $\left(\mathrm{kg} / \mathrm{m}^{3}\right)$

15. F - reflec. frac. of $r$

16. $T_{\min }$ - min. ref. $T(m)$

17. $T_{\max }-\max$. ref. $T(m)$

18. $T_{f 1 x}-f 1 x T(m)$

19. $p_{\text {rf }}$ - ref1. dens $\left(\mathrm{kg} / \mathrm{m}^{3}\right)$

20. n - press. vess. locator

21. U - press. vess. (MPa) strength

22. $p_{p v}$ - press. vess. dens. ( $\left.k g / \mathrm{m}^{3}\right)$

23. $P_{r}$ - coolant press. (MPa)

24. $p^{r}-$ M1s. Mass fraction

RSMass Input Data

(Pin) Value

0.25
0.7
0
28
0.6
13.500
1.0
0.065
0.5
1.3
0
1
0.65
12.000
0.5
0.05
0.20
0
3.000
1
280
8,000
0.5
0.5

.0

.5

0.05

.20

00

0.5

\section{Alternate}

DATE: $1 / 29 / 86$

(PIn)

Parameter

25. $D_{n} \quad$ - n-shield dose limit (nrt)

26. $D_{Y}-Y$-dose limit (R)

27. RP - payload distance $(m)$

28. $\Sigma_{c} \quad$ - core remov. $x-\sec \left(\mathrm{cm}^{-1}\right)$

29. $\mu_{c}$ - core Y-atten. $x-\sec \left(\mathrm{cm}^{-1}\right)$

30. I $\quad$ - sh1eld n-removal $x-\sec \left(\mathrm{cm}^{-1}\right)$

31. $I_{r}^{Y}-Y$-shield $n$-removal $x-\sec \left(\mathrm{cm}^{-1}\right)$

31. Ir $r$ - $\mu_{n}$-shield n-removal $x-\sec \left(\mathrm{cm}^{-1}\right)$

32. Hn
33. $H_{Y}-$ - Y-shield $Y$-atten. $X-\sec \left(\mathrm{cm}^{-1}\right)$
34. $\theta$

34. $\theta \quad-$ cone $1 / 2$ angle (deg.)

35. $P_{n s}-n$-shleld dens. $\left(\mathrm{kg} / \mathrm{m}^{3}\right)$

36. Prs $-Y$-shield dens. $\left(\mathrm{kg} / \mathrm{m}^{3}\right)$

37. PYs

37. $A_{1}$

38. $\left.\begin{array}{ll}a_{1} \\ \text { 39. } & a_{2}\end{array}\right\}$

39. $\mathrm{P}_{2}$

40. $P_{s}-$ mult. on $r$ for $L_{s}$

41. $P_{n} \quad-$ mult. on $t_{n}$ for $t_{2}$

- mult on $t$ for

43. 9 - geomet $g$ for 1 or

$\begin{array}{lll}\text { 43. } 6 g & \text { - geomet. correction for } Y \text {-shield } & 1 \\ \text { 44. } 6 \text { - geomet. correc. for n-shield } & 1\end{array}$
Alternate

$10^{15}$

$10^{6}$

25

0.125

0.136

0.2

0.029

0.78

15

820

9.350

2.7

$-0.086$

0.134

5

.5 
REACTOR: Thermionic (conventional)

\begin{tabular}{|c|c|c|}
\hline & Parameter & value \\
\hline & Reactor & \\
\hline 1. & - efficlency & 0.15 \\
\hline 2. c & - enrichment & 0.93 \\
\hline 3. $\mathrm{R}$ & - mod ratio & $\mathbf{0}$ \\
\hline 4. $M_{c}^{c}$ & - compact crlt. mass (kg) & 28 \\
\hline 5. VF & - fuel + mod. vol. frac. & 0.36 \\
\hline 6. $P_{p}$ & - fuel dens. $\left(\mathrm{kg} / \mathrm{m}^{3}\right)$ & 10,000 \\
\hline 7. $\mathrm{c}$ & - crit. mass correc. & 1 \\
\hline 8. $\boldsymbol{\beta}$ & - burnup 11mit & 0.06 \\
\hline 9. $P_{8}$ & - spec. power llalt (m/kg) & 0.01 \\
\hline 10. $P_{p}$ & - peak/avg. power & 1.3 \\
\hline 11. & $-\bmod . \operatorname{mol} . w t .(g)$ & o \\
\hline 12. P & - mod. dens. $\left(\mathrm{kg} / \mathrm{m}^{3}\right)$ & 1 \\
\hline 13. & - struc./fuel + mod. volume & 2 \\
\hline 14. $P_{8}$ & - struc. dens. $\left(\mathrm{kg} / \mathrm{m}^{3}\right)$ & 12,000 \\
\hline 15. & - reflec. frac. of $r$ & 0.35 \\
\hline 16. $T_{R}$ & $-m i n . r e f . T(m)$ & 0.05 \\
\hline 17. $T$ & $-\max$. ref. I (m) & 0.20 \\
\hline 18. $T_{f}$ & $-\boldsymbol{E} \mathbf{1} \mathbf{I}(\mathbf{m})$ & $\mathbf{0}$ \\
\hline 19. $P_{\mathrm{r}}$ & - ref 1. dens $\left(\mathrm{kg} / \mathrm{m}^{3}\right)$ & 2,200 \\
\hline 20. $\mathrm{n}$ & - press. vess. locator & 1 \\
\hline 21. $u_{8}$ & - press. vess. (RPa) strength & 280 \\
\hline 22. $P_{p}$ & - press. vess. dens. $\left(\mathrm{kg} / \mathrm{m}^{3}\right)$ & 8,000 \\
\hline 23. $\mathbf{P}_{\mathbf{r}}$ & - coolant press. (MPa) & 0.2 \\
\hline 24. $F$ & - Mis. Mass Praction & 0.5 \\
\hline
\end{tabular}

RSuss Input Data

DATB: $1 / 29 / 86$

Alternate

Value

Aternate

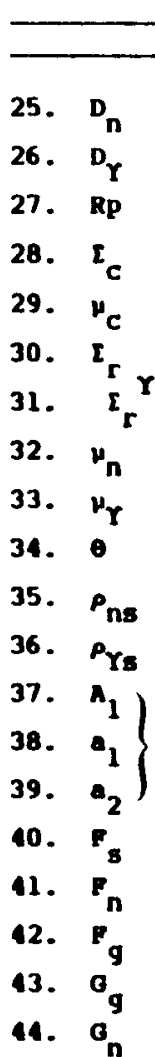

shield

$10^{15}$

$10^{6}$

25

0.14

0.96

0.136

0.20

0.029

0.78

15

820

- n-shield dens. $\left(\mathrm{kg} / \mathrm{m}^{3}\right)$

- Y-shield dens. $\left(\mathrm{kg} / \mathrm{m}^{3}\right)$

19.350

shielding parameters

$-0.086$

0.134

- mult. on $r$ for $L$

- mult. on $t_{n}$ for $t_{2}$

- mult. on $t_{g}$ for $t_{1}$

- geomet. correction

- geamet. correc. for n-shleld
3

0.5 


\subsection{COMPARISON WITH DETAILED CALCULATIONS}

A comparison has been completed of the reactor/shield masses obtained from detailed calculations by the proposers of space power reactors (References 6 through 17) with the masses calculated by RSMASS for these proposed reactors. An initial goal for agreement between RSMASS calculated masses and the masses obtained from detailed calculations was chosen to be a factor of two. Discrepancies greater than a factor of two would be indicative of either a modeling deficiency by RSMASS, an inappropriate parameter choice for RSMASS, or an error in the detailed calculations.

Figure 3 compares the RSMASS reactor/shield masses for liquid metal cooled reactors with the masses calculated by various laboratories for their proposed reactors. Except for the Rockwell SP-100 reactor, all of the reactors are for MMW power. Good agreement is observed for all of the proposed reactors. A similar comparison was made for thermionic reactors. The two cases shown in Figure 4 are General Atomic's (GA) SP-100 and their 2 MW "growth" design. Again. the agreement is good. (A direct comparison of these thermionic reactor masses with masses for other types of reactors may be misleading since these designs have not been optimized for MMW requirements. Also, a system mass analysis is required to evaluate the net mass impact of thermionic reactors relative to other concepts since the thermionic reactor mass also includes the power conversion system mass.)

Figure 5 compares the reactor/shield masses for Brookhaven National Laboratory's (BNL) gas cooled reactors with the masses calculated by RSMASS. It should be pointed out that the calculated gas cooled reactor masses appear to be very sensitive to the reactor input parameter choices and some values for gas cooled reactor parameters are only an educated guess at this time (such as the moderator-to-fuel ratio, the critical mass correction factor, and the specific power limit). Nonetheless, the RSMASS calculated reactor mass is in good agreement with BNL's masses for both the $\mathrm{ZrH}_{1} 7$ moderated bimodal concept and the LiH moderated burst mode reactor concept.

A number of other comparisons and studies are now under way. In some instances RSMAss has uncovered oversights in the more detailed calculational efforts. RSMAss is also providing some insights into the mass advantages and disadvantages for the various concepts as a function of operating conditions and as a function of important parameters (such as fuel density). When these studies have been completed a report will be provided which will discuss the results of the analysis. For now, it may be concluded that 
RSMASS çan provide good estimates of reactor and shield masses for a broad variety of reactor concepts proposed for MMW space power applications. These estimates will probably not be more than $50 z$ different than masses computed using more detailed and time consuming calculation methods; much better than our original goal. 


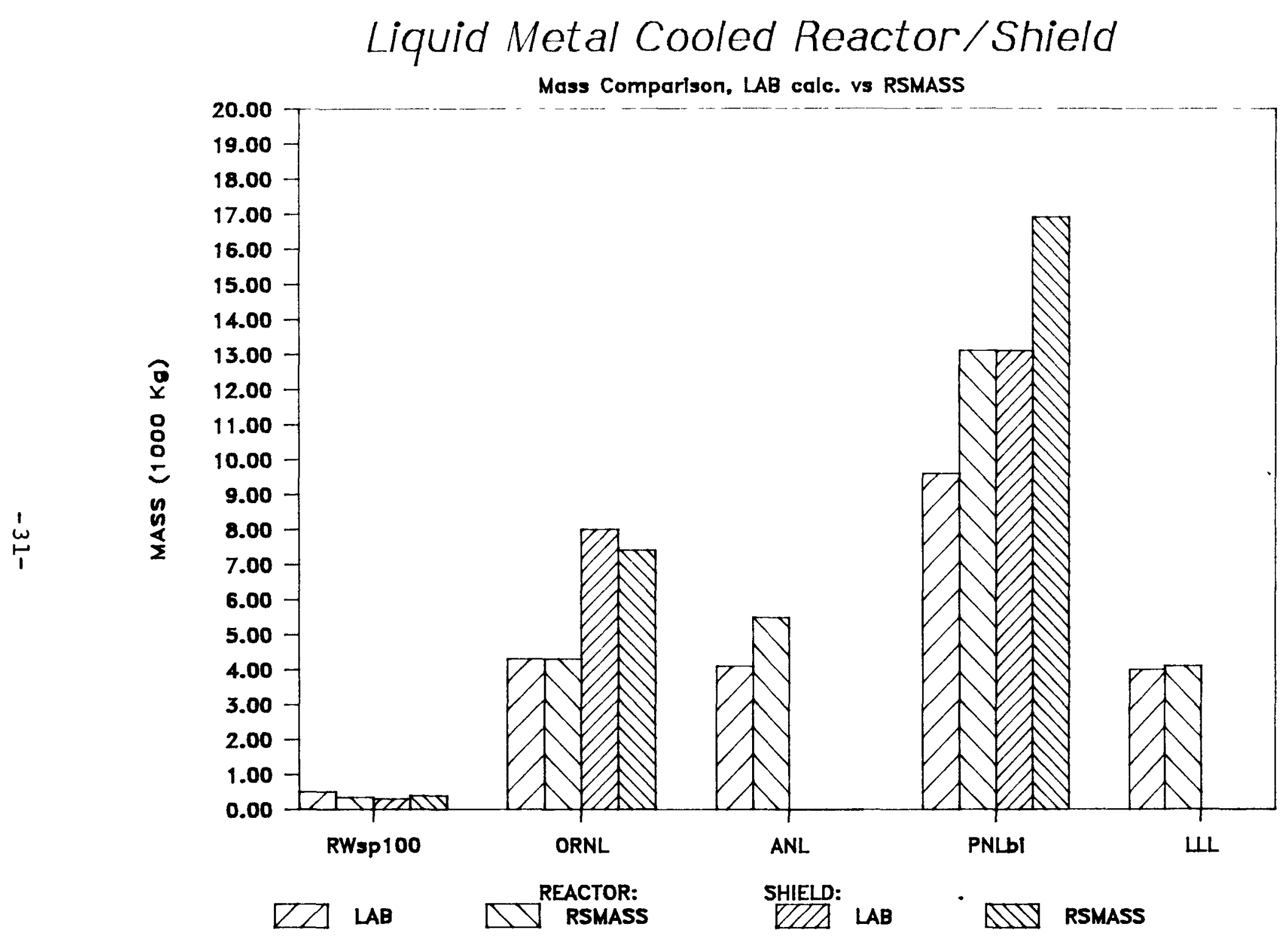

Figure 3. Liquid Metal Cooled Reactor/Shield 
Thermionic Reactor/Shield

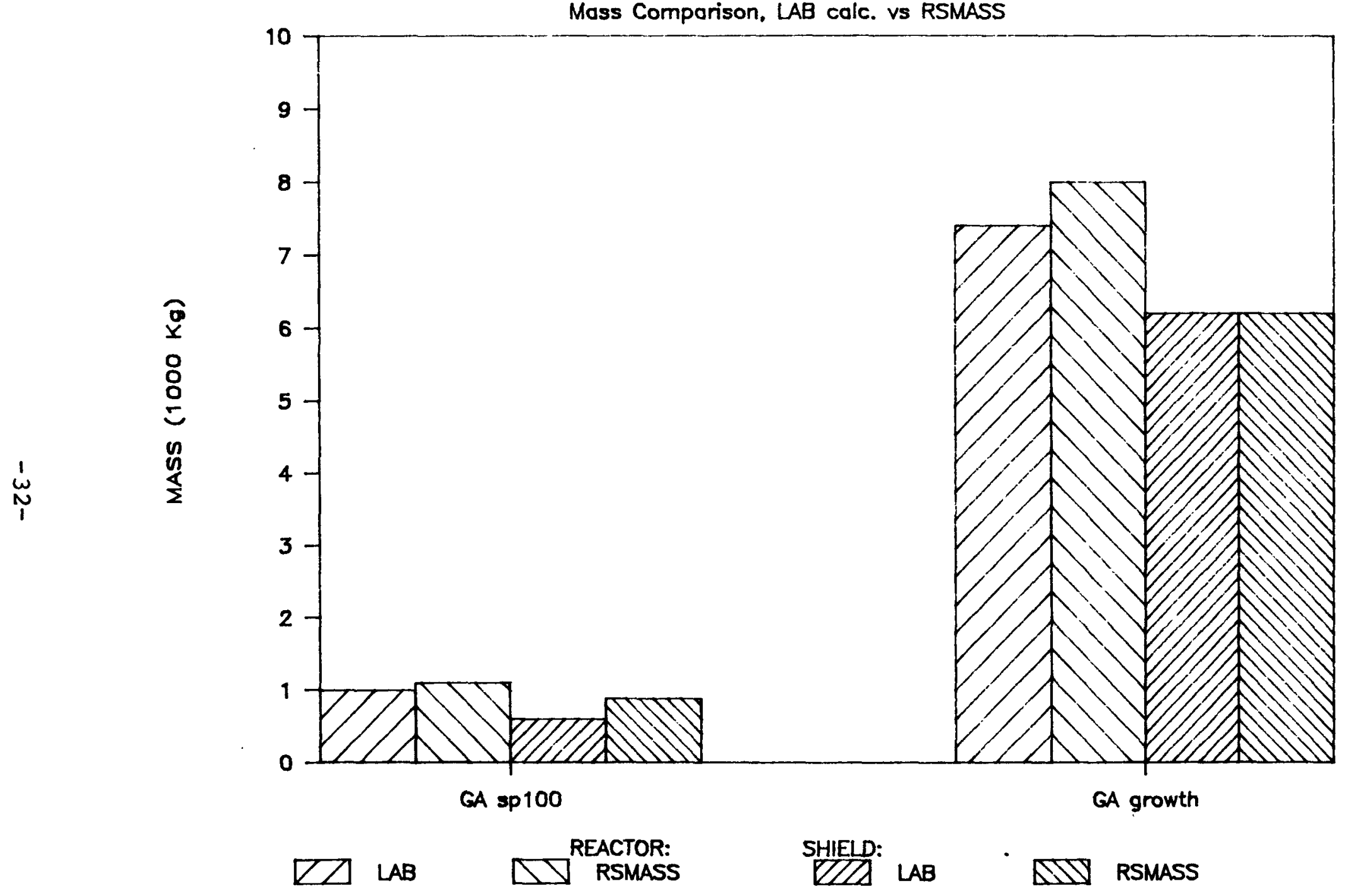

Figure 4. Thermionic Reactor/Shield 


\section{Gas Cooled Reactor}

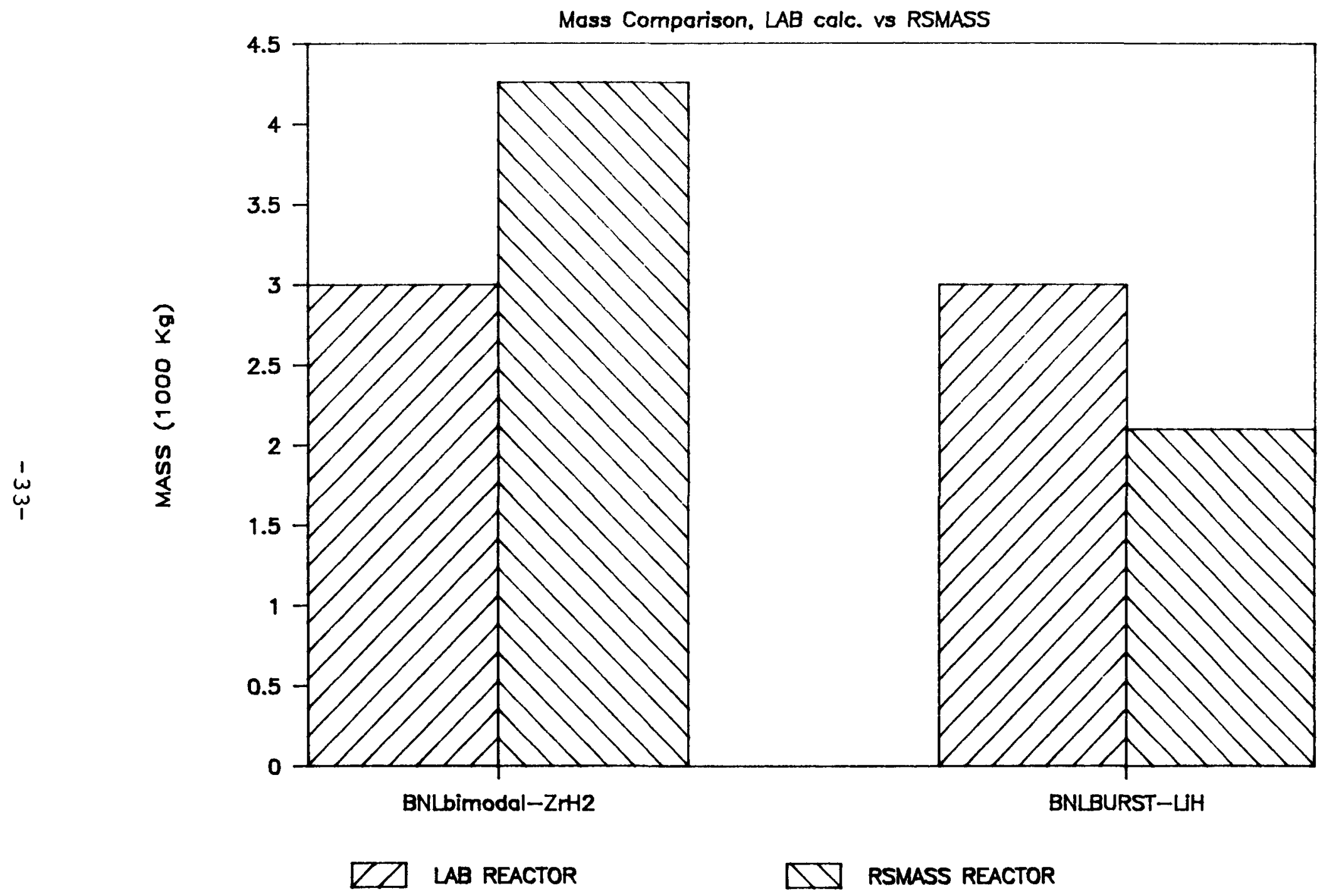

Figure 5. Gas Cooled Reactor 
The preliminary reactor/shield mass modeling has been completed. The next order of business will be to obtain more accurate input parameters for the models. to obtain input parameters for other types of reactors, and to continue checking the models against more detailed calculations. Once the model has been verified, a preliminary parameter study will be performed and the results will be discussed in a forthcoming document. A method that will provide corrections for parasitic absorbers will also be discussed in this forthcoming document. 


\subsection{REFERENCES}

1. Ranken, W. A., Space Reactors, LA-9379-PR, UC-33, July-September Progress Report, issued June 1982.

2. Reactor Physics Constants, Argonne National Laboratory. ANL5800, JulY 1963.

3. Paxton, H. C., Criticality in operations with Fissile Materials. LA-3366 (Rev). November 1972 .

4. Glasstone and Sesonske, Nuclear Reactor Engineering (Van Nostrand Reinhold Co.. 1967).

5. Rockwel1. Theodore III, Reactor Shielding Design Manual. USAEC. 1956.

6. Proposal on Refinement of Multimegawatt space Reactor Power system Concepts. Argonne National Laboratory. ANL SPC-26. April 29, 1985 .

7. Evaluation of Multimegawatt space Power Plants for Air Force Missions, Argonne National Laboratory, ANL SPC-3. April 20, 1984.

8. Powel1. J.. Strategic Defense Applications of Particle Bed Reactors, Brookhaven National Laboratories. April 30, 1985.

9. Powel1. J., Design and Technology of Multimegawatt Particle Bed Reactors. Brookhaven National Laboratories. April 17. 1984 .

10. Revised MMW Implementation Plans. Chapters 2, 4, and $7(U)$. Oak Ridge National Laboratory. April 11. 1985.

11. Phase I study of Multimegawatt Space Power systems. Oak Ridge National Laboratory. April 13. 1984.

12. Walter, C.. et al.. Technology Development Plan for Multi-Megawatt space Power systems (U). May 1984.

13. Barner, J.. et al.. Rotating Multi-Megawatt BoilingLiquid-Metal Reactor (RMBLR) Conceptual Design (U). Pacific Northwest Laboratories, April 1984.

14. Coombs, et al.. Personal Communication with staff. Pacific Northwest Laboratories, December 1985.

15. SP-100 Sterling Engine Conversion System Design Concept Studies - Final Overview Proqram Briefing. Al-NASA-BD-85-24, Rockwell International, May 8, 1985. 
16. Thermionic space Power systems - Summary Briefing. GA-C17976, GA Technologies, Martin Marietta, May 9. 1985 .

17. Fisher, C. R., et al., Growth Versions and Options for the Thermionic Power system, GA Technologies, Internal Memorandum.

18. McDaniel. P. J. and J.M. Harris, A Theoretical Analysis of the Effect of Thermal Neutron Absorbers on Dual Detector Porosity Log Measurements. AMS Transactions. October 30-November 4. 1983 .

19. Alcouffe, R. E.. et al.. Users Guide for TWODANT LA-10049-M, October 1984 . 
APPENDIX 1

Effect of Fuel Density on Critical Mass 
Figure 9 in Reference 3 shows that the critical fuel mass is not strongly dependent on the molecular composition of the fuel (UC $2 . \mathrm{UO}_{2}$. etc.): consequently. Figure 1 should be applicable to any fuel composition. Figures 9 and 16 in Reference 3, however. show that the critical mass is a strong function of fuel density. The functional dependence of the critical mass on fuel density is derived in the following.

The effective neutron multiplication factor (keff) can be expressed as:

$$
k_{\text {eff }} \approx \frac{k_{\infty}}{1+L^{2} B^{2}}
$$

where $k_{\infty}=$ the neutron multiplication factor for an infinite medium.

$L=$ diffusion length--related to the effective distance a neutron travels from birth to capture, and

$\mathrm{B}^{2}=$ buckling--a geometric factor determining neutron leakage.

If we assume a spherical reactor,

$$
B^{2}=(\pi / r)^{2}
$$

Then from (A-1) for just critical systems

$$
\frac{k_{\infty}}{1+L_{C}^{2}\left(\pi / r_{C}\right)^{2}}=\frac{k_{\infty}}{1+L^{2}(\pi / r)^{2}}
$$

where the subscript $C$ refers to the compacted sphere case and the parameters without subscripts refer to reactor cases with lower fuel densities. But 


$$
-L^{2} \sim \frac{1}{\sum_{a} \Sigma_{t r}}
$$

where $\Sigma_{t r}=$ macroscopic transport cross section, and since $\Sigma \sim \rho$ (where $\rho=$ density), then $L \sim 1 / \rho$.

Now from $(A-2)$

$$
\left(L_{C} / r_{C}\right)^{2}=(L / r)^{2}
$$

or

$$
r / r_{C}=L / L_{C}=\rho_{C} / p
$$

Since $\quad M=\rho \frac{4}{3} \pi r^{3}=$ mass of fuel

$$
\frac{M}{M_{C}^{C}}=\frac{\rho}{\rho_{C}}\left(\frac{r}{r_{C}}\right)^{3} .
$$

where $M_{C}^{C}$ is the compacted critical mass. Substituting from $(A-5)$

$$
\frac{M}{M_{C}^{C}}=\frac{\rho}{\rho_{C}}\left(\frac{\rho_{C}}{\rho}\right)^{3}=\left(\frac{\rho_{C}}{\rho}\right)^{2} .
$$

Since $\rho$ is the homogenized density, we can express $\rho$ in terms of the unhomogenized fuel density $\left(\rho_{F}\right)$ and the fuel volume fraction. The critical mass correction factor for density is then:

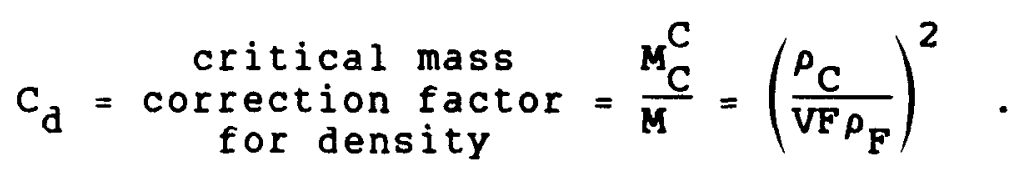

For full density UC, $\rho_{C}=13,600 \mathrm{~kg} / \mathrm{m}^{3}$. Therefore, 


$$
c_{d}=\left(\frac{13,600}{V F \rho_{F}}\right)^{2}
$$

However. since the reflector density will not change (reflector density change is implicitly assumed in this derivation). $c_{d}$ is overestimated. From the data in Reference 3. the density-volume fraction correction is found to be better approximated by:

$$
c_{\mathrm{d}}=\left(\frac{13,600}{\mathrm{VF} \rho_{\mathrm{F}}}\right)^{1.5}
$$




\section{APPENDIX 2}

Enrichment Correction to Critical Mass 


\section{APPENDIX 2 \\ Enrichment Correction to Critical Mass}

For fast and epithermal reactors we can assume that the product of the fast fission and resonance escape factors is approximately unity. Then.

$$
k_{\infty} \approx \frac{v \Sigma_{f}}{\Sigma_{a}}
$$

where

$$
v=\text { neutrons/fission. }
$$

$\Sigma_{f}=$ macroscopic fission cross section, and

$\Sigma_{a}=$ macroscopic absorption cross section.

Then from (A-1) for a critical reactor.

$$
1+\frac{\pi^{2}}{3 \Sigma_{t r} \Sigma_{a} r^{2}}=\frac{v \Sigma_{f}}{\Sigma_{a}}
$$

or

$$
r=\left[\frac{\pi^{2}}{3 \Sigma_{t r} \Sigma_{a}}\left(\frac{1}{\frac{v \Sigma_{f}}{\Sigma_{a}}-1}\right)\right]^{1 / 2} .
$$

since $M \sim \rho r^{3}$. and noting that $\Sigma_{t r}$ is insensitive to changes in $\varepsilon$.

$$
M \sim\left[\frac{1}{\Sigma_{a}}\left(\frac{1}{\frac{v \Sigma_{f}}{\Sigma_{a}}-1}\right)\right]^{3 / 2} .
$$

Now.

$$
\frac{\Sigma^{f}}{\Sigma_{a}} \approx \frac{N^{25} \sigma^{25}}{N^{25} \sigma_{a}^{25}+N^{28} \sigma_{a}^{28}} .
$$


Here. $\quad-\mathbf{N}=$ uranium atom density.

$$
\begin{aligned}
& 25=\mathrm{U}-235 . \\
& 28=\mathrm{U}-238 . \\
& \sigma_{\mathrm{f}}=\text { microscopic fission cross section, and } \\
& \sigma_{\mathrm{a}}=\text { microscopic absorption cross section. }
\end{aligned}
$$

The atom densities for $U^{235}$ and $U^{238}$ are

$$
\begin{aligned}
& \mathbf{N}_{25}=\varepsilon N \\
& N_{28}=(1-\varepsilon) N .
\end{aligned}
$$

Substituting $(A-16)$ and $(A-17)$ into $(A-15)$ we have for a reactor with enrichment $\varepsilon$ :

$M_{L \varepsilon} \sim\left[\frac{1}{\varepsilon N \sigma_{a}^{25}+(1-\varepsilon) N \sigma_{a}^{28}}\left(\frac{1}{\frac{v \in N \sigma_{f}^{25}}{\varepsilon N \sigma_{a}^{25}+(1-\varepsilon) N \sigma_{a}^{28}}-1}\right)\right]^{3 / 2} \cdot(A-18)$

where $M_{L \varepsilon}=$ mass for lower enrichment case. and for a fully enriched system $\left(M_{0}\right)$

$$
M_{0} \sim\left[\frac{1}{N \sigma_{a}^{25}}\left(\frac{v N \sigma_{f}^{25}}{N \sigma_{a}^{25}}-1\right)\right]^{3 / 2}
$$

Ratioing $(A-18)$ to $(A-19)$ and canceling, we have

$$
\frac{M_{L \varepsilon}}{M_{0}}=\left[\frac{1}{\varepsilon-(1-\varepsilon)\left(\frac{\sigma_{a}^{28}}{v \sigma_{f}^{25}-\sigma_{a}^{25}}\right)}\right]^{3 / 2}
$$


For fast reactor $v=2.6 . \sigma_{\mathrm{f}}^{25} \approx 1.4 . \sigma_{\mathrm{a}}^{25} \approx 1.65 . \sigma_{\mathrm{a}}^{28} \approx 0.26$. and for thermal reactors $v=2.4 . \sigma_{f}^{25} \simeq 577 . \sigma_{a}^{25} \simeq 676$. $\sigma_{a}^{28} \simeq 2.7$.

substituting. we obtain:

$$
\frac{M_{L_{\varepsilon}}}{M_{0}} \approx\left(\frac{1}{\varepsilon}\right)^{3 / 2}
$$

However, as in Appendix 1. the reflector characteristics are not affected by changes in the enrichment, and, using the same approximate reduction in the power of the exponent. we can make the crude approximation:

$$
\frac{\mathbf{M}_{L_{\varepsilon}}}{M_{0}} \approx \frac{1}{\varepsilon}
$$

A comparison of this approximation with detailed calculational results in Reference 4 showed this approximation to be reasonable for fast reactors ( 20 percent). 


\section{APPENDIX 3}

Fission Products and Temperature Defect 


\section{APPENDIX 3}

Fission Products and Temperature Defect

Fission products and increased absorptions due to the temperature increase at full power will reduce the core reactivity. If we use the definition for reactivity change:

$$
\Delta p=\underset{\begin{array}{c}
\text { change } \\
\text { reactivity }
\end{array}=\frac{k_{\text {eff }_{2}-k_{\text {eff }}}}{k_{\text {eff }} k_{\text {eff }}}}{.}
$$

(note that $\rho$ as used in Appendix 3 will stand for reactivity rather than density).

We can compute the effect of reactivity change on the core size from $(A-1)$ and $(A-23)$ as:

$$
\left(\frac{r_{2}}{r_{1}}\right)^{2}=\frac{\Delta \rho r_{2}^{2}}{\pi^{2} L^{2}}+\Delta \rho+1
$$

For reactors under consideration, $r_{2}^{2} / \pi^{2} L^{2}$ is $<1.0$; therefore, when reflector effects are accounted for (as in Appendix 1) the maximum change in mass is given by:

$$
\frac{M_{2}}{M_{1}}<(1+2 \Delta \rho)^{1.5} .
$$

Thus, the change in mass required for the combined effects of fission products and temperature defect, if the combined worth is assumed $\approx \$ 3.00(\Delta p=0.023)$. is less than 7 percent. The effect of fission products and temperature will consequently be ignored. 
APPENDIX 4

Shielding Thickness Derivations 


\section{APPENDIX 4}

\section{Shielding Thickness Derivations}

since the shield will be very close to the reactor for most MMW systems, a point source approximation is not appropriate. and any source term must include volumetric parameters. The total source that must be considered will be proportional to the source density integrated over the surface area "seen" by the shield. The source strength will be proportional to the average power density multiplied by the fraction of radiation leaving the end surface (A) of the reactor (see Figure 6 ). Since most of the radiation will be absorbed in the reactor volume. only a fraction proportional to $1 / \mu_{C}$ will reach surface $A$ ( $\mu_{C}$ is the core selfabsorption coefficient). From this discussion. it is seen that the total source strength is proportional to:

$$
\begin{aligned}
& s \sim \begin{array}{c}
\text { power } \\
\text { density }
\end{array} \frac{1}{\mu_{C}} \times A=\begin{array}{c}
\text { total } \\
\text { source } \\
\text { strength }
\end{array} \\
& \text { or } \quad s \sim \frac{P}{r^{3}} \times \frac{1}{\mu_{C}} \times r^{2} \\
& s \sim \frac{P}{r \mu_{C}} .
\end{aligned}
$$

It is anticipated that the payload will always be several meters from the shield; consequently. the radiation attenuation through the shield can be approximated by (Reference 5):

$$
\exp (-\mu t)
$$

and the solid angle radiation attenuation between the reactor and shield is given by the familiar:

$$
\frac{1}{R_{P}^{2}}
$$

where $\mu=$ generalized attenuation coefficient for shield.

$$
t=\text { shield thickness. and }
$$




\section{GEOMETRY OF REACTOR/SHIELD ASSUMED FOR DOSE DERIVATION}

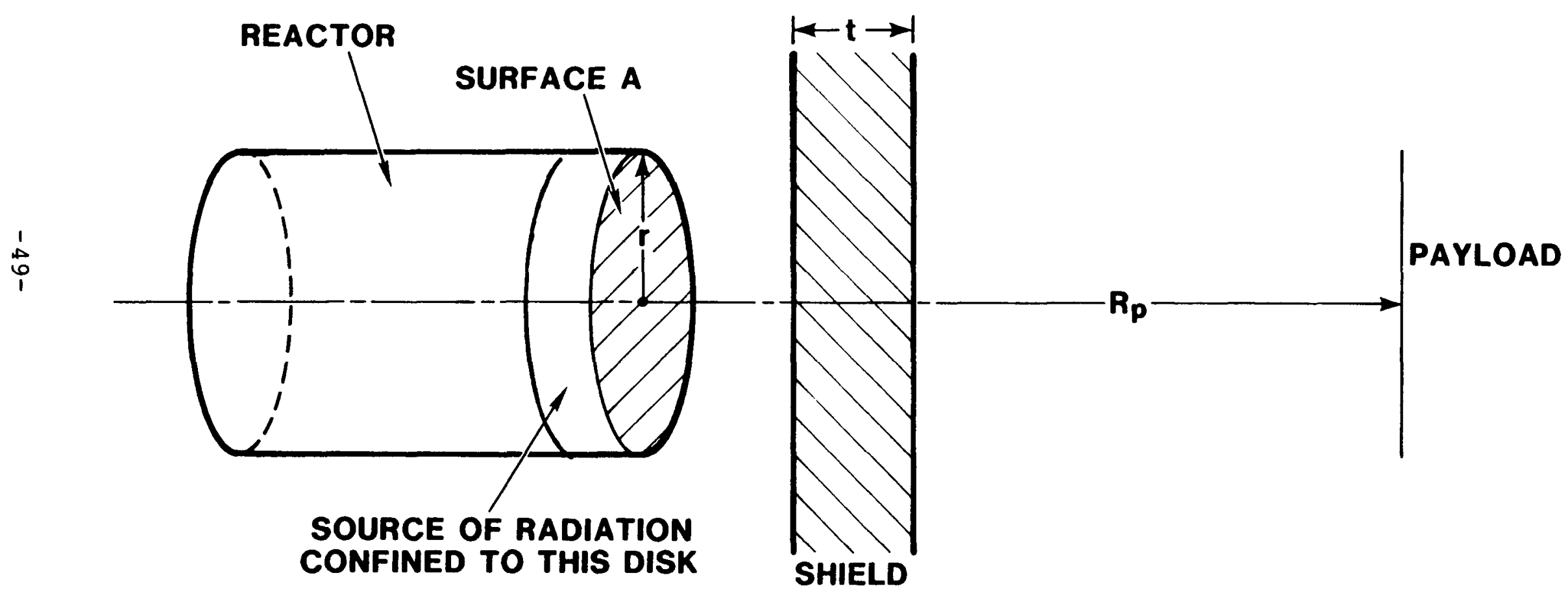

Figure 6. Geometry of Reactor/Shield Assumed for Dose Derivation 


$$
\begin{aligned}
& R_{P}= \text { distance between reactor surface }(A) \text { and pay- } \\
& \text { load. }
\end{aligned}
$$

The total dose at the payload will depend on the time integral of the dose rate at the payload. The integral dose at the payload is, therefore, proportional to:

$$
\begin{aligned}
& D_{R} \sim \frac{P}{r \mu_{C}} \frac{\exp (-\mu t)}{R_{P}^{2}} \times \text { time } \\
& \text { or } \quad D_{R}=C \frac{\operatorname{Eexp}(-\mu t)}{\operatorname{er} \mu_{C} R_{P}^{2}}
\end{aligned}
$$

where $D_{R}=$ dose at location $R_{d}(R)$.

$$
\begin{aligned}
& E=\text { electrical energy (MW years). } \\
& e=\text { net fractional efficiency, and } \\
& C=\text { constant of proportionality. }
\end{aligned}
$$

(Note that for gamma shield calculations the gamma dose due to neutron captures in the shield has not been explicitly accounted for. It is also assumed that the gamma dose at the payload can be computed by using coefficients for a single energy. From the data in Reference 1 it appears that $3 \mathrm{MeV}$ gammas can be used for this approximation.)

Although the approximate relationship described above should provide a reasonable estimate of the influence of variations in the important parameters, this approach is not very reliable for determining the absolute value of the dose $\mathrm{D}_{\mathrm{R}}$. A much more reliable method would require very time consuming, detailed Monte Carlo calculations, which would be impractical for our purposes. In order to provide reasonable accuracy while maintaining the simplicity of Equation $(A-30)$. the parameters from a detailed Monte carlo calculation (Reference 1 ) were used in Equation (A-30) to determine the normalization coefficient $C$. The values obtained for $C$ are given below.

\begin{tabular}{ll} 
& \multicolumn{1}{c}{$\mathrm{C}$} \\
\cline { 2 - 2 } Neutrons & $6.6 \times 10^{16}$ \\
Gammas & $1.0 \times 10^{9}$
\end{tabular}




\section{DISTR IBUTION :}

DOE-TIC 4500 UC-80 (129 copies)

Air Force Center for Studies \& Analyses/SASD

The Pentagon, Room 1D-431

Washington, DC 20330-5420

Attn: w. Barattino, AFCSA/SASD

Air Force Space Technology Center/SWL

Kirtland AFB. NM 87117-6008

Attn: M. Brasher

Air Force Space Technology Center/SwL Kirtland AFB, NM 87117-6008

Attn: J. DiTucci

Air Force Space Technology Center/SWL Kirtland AFB, NM 87117-6008

Attn: E. Fornoles

Air Force space Technology Center/TP

Kirtland AFB, NM 87117-6008

Attn: M. Good

Air Force Space Technology Center/XLP

Kirtland AFB, NM 87117-6008

Attn: A. Huber

Air Force Space Technology Center/swL

Kirtland AFB, NM 87117-6008

Attn: S. Peterson

The Aerospace Corporation

P.O. Box 9113

Albuquerque, NM 87119

Attn: W. Zelinsky

Argonne National Laboratory

$9700 \mathrm{~S}$. Cass Avenue

Argonne, IL 60439

Attn: S. Bhattacharyya

Argonne National Laboratory

9700 S. Cass Avenue

Argonne. IL 60439

Attn: R. Lewis

Brookhaven National Laboratory

Bldg. 701. Leve1 143

Upton, NY 11973

Attn: J. Powell 
Distribution (cont'd):

Boeing Aerospace

P.O. Box 3999

Seattle. WA 98124-2499

Attn: A. Sutey, MS $8 \mathrm{C}-27$

Defense Nuclear Agency

6801 Telegraph Road

Alexandria, VA 22310-3398

Attn: J. Farber/RAEV

U. S. Department of Energy

NE- 521

E419/GTN

Germantown, MD 20545

Attn: I. Helms

U. S. Department of Energy

OSRP /NE-54, GTN

Germantown. MD 20545

Attn: E. Khan (10 copies)

U. S. Department of Energy

NE-54

D411/GTN

Germantown. MD 20545

Attn: W. Nelson

U. S. Department of Energy

NE- 521

F415/GTN

Germantown. MD 20545

Attn: E. Wahlquist

GA Technologies, Inc. P.O. Box 85608

San Diego, CA 92138

Attn: R. Dahlberg

GA Technologies, Inc.

P.O. BOX 85608

San Diego, CA 92138

Attn: C. Fisher

GA Technologies. Inc. P.O. BOX 85608

San Diego, CA 92138

Attn: G. Fitzpatrick 
Distribution (cont'd):

General Electric Company

P.O. Box 8555

Space Division

Philadelphia, PA 19101

Attn: R. J. Katucki

House of Representatives

Committee on science and Technology

B-374 Rayburn House office Building

Washington, DC 20515

Attn: N. L. Milder

International Energy Associates, Inc.

1717 Louisiana NE

Suite 202

Albuquerque, NM 87123

Attn: G. B. Varnado

Los Alamos National Laboratory

P.O. Box 1663

Los Alamos, NM 87545

Attn: T. Trapp, MS-E561

Los Alamos National Laboratory

P.O. Box 1663

Los Alamos. NM 87545

Attn: R. Hardie, MS-F611

Los Alamos National Laboratory

P.O. Box 1663

Los Alamos, NM 87545

Attn: S. Jackson, MS-F611

Los Alamos National Laboratory

P.O. Box 1663

Los Alamos, NM 87545

Attn: R. Bohl, MS-K551

Lawrence Livermore National Laboratory

P.O. Box 808

Livermore, CA 94550

Attn: C. E. Walter. MS L-144

NASA Lewis Research Center

21000 Brookpark Road

Cleveland, OH 44135

Attn: D. Bents, MS 301-5

NASA Lewis Research Center

21000 Brookpark Road

Cleveland. OH 44135

Attn: Barbara Jones, MS 301-5 
Distribution (cont'd):

NASA Lewis Research Center

21000 Brookpark Road

Cleveland. OH 44135

Attn: A. Juhasz, MS 301-5

NASA Lewis Research Center

21000 Brookpark Road

Cleveland, $\mathrm{OH} \quad 44135$

Attn: J. Smith, MS 301-5

NASA Lewis Research Center

21000 Brookpark Road

Cleveland. OH 44135

Attn: J. Sovie. MS $301-5$ ( 5 copies)

Oak Ridge National Laboratory

P.O. BoX Y

Bldg. 9201-3, MS-7

Oak Ridge. TN 37831

Attn: J. P. Nichols

Battelle Pacific Northwest Labs

P.O. Box 999

Richland, WA 99352

Attn: R. Widrig

Science Applications. Inc.

505 Marquette Avenue NW

Albuquerque. NM 87102

Attn: D. Buden

SDI Organization

OSD Mailroom, The Pentagon

Washington, DC 20301-7100

Attn: R. Verga

SDI Organization

OSD Mailroom. The Pentagon

Washington, DC 20301-7100

Attn: R. Wiley

$\mathrm{SDIO} / \mathrm{KE}$

The Pentagon

Washington, DC 20301-7100

Attn: $R$. $X$. Lenard

Space Power. Inc.

253 Humboldt Court

Sunnyvale. CA 94089

Attn: J.R. Wetch 
Distribution (cont'd):

University of New Mexico

Chemical and Nuclear Engineering Department

Albuquerque, NM 87131

Attn: M. El-Genk

W. J. Schafer Associates

1901 North Ft. Myers Drive

Rosslyn, VA 22209

Attn: P. Mace

Westinghouse Electric

P.O. Box 158

Madison, PA 15663-0158

Attn: L. Hedgecock

Westinghouse Electric

P.O. BOX 158

Madison, PA 15663-0158

Attn: J. Chi

0332 J. Keizur

0332 L. Connell

0332 R. Zazworsky

$1240 \mathrm{~K}$. Prestwich

1270 R. Miller

1271 M. Clauser

3141 S. A. Landenberger (5)

3151 W. L. Garner (3)

6423 P. Pickard

$6430 \quad$ N. Ortiz

6431 J. Philbin

6433 J. Aragon

6433 L. Cropp

6433 M. Edenburn

6433 D. Gallup

$6433 \mathrm{~J}$. Lee

6433 A. Marshall (10)

6433 W. McCulloch

6433 P. McDaniel

6433 F. Thome

6433 F. Wyant

8024 P. W. Dean 